suggestive of a congenital infection, which would have been unnoticed unless one had looked for them specially-for example, gapped teeth and an increased carrying angle of the elbow joints.

Dr. Nicol, replying to the discussion, said that the problem of post-lumbar-puncture headaches had been a very real one in the old days. He had always taught students (and did so still) that if they were going to do lumbar punctures-at any rate so far as neurosyphilis cases were concerned - they should use the Dattner needle and, if necessary, carry out the procedure in the out-patients department. If this fine needle was used patients did not get headaches. Dr. Whelen's practice was to allow the patient to get up and go home within as short a time as a quarter of an hour of the lumbar puncture.

Concerning asymptomatic congenital cases, he wondered how far some of those cases to which the President had alluded were juvenile acquired cases. In the series at Horton Hospital, which extended to over 2,000 cases, he had come across a number in which the syphilis had been acquired when the patient was a juvenile. These patients had fully developed general paralysis of the insane at the age of 25-30 years; this was rather old for the congenital case, although a few cases were undoubtedly congenital. He had felt, however, that some of these were quite possibly acquired cases, and a careful follow-up had often confirmed this suspicion.

Dr. McFarlane had suggested treating these patients with neoarsphenamine to start with and then, if they did not improve, resorting to sterner measures. He agreed, but it had to be remembered that many of the Horton cases had already had a good deal of treatment before admission. In 1937, when Dr. Hutton and he read a paper to the Society, they were absolutely certain that in some of these patients, in spite of receiving regular and constant doses of N.A.B. (neoarsphenamine), general paralysis finally developed.

Dr. Stuart had mentioned the question of desensitizing the patients. He understood that the Americans had done that, but he personally, in the few cases with toxic symptoms, suspended any further treatment with tryparsamide. During the recent war he had seen a paper from the United States of America in which it was noted that the toxicity relative to tryparsamide was very much higher in recent years than it had been 20 years ago, when first employed, and the writer of the paper had raised the question whether there was something in the process of manufacture which made it more toxic.

Returning to the -problem of penicillin, at Horton Hospital they had been beginning to use penicillin rather on the lines of those employed at the Naval Auxiliary Hospital at Knowle, giving 300,000 units of penicillin daily up to $4: 2$ mega units. That course lasted for a fortnight. One or two cases had been tested already in which penicillin had been recovered in the cerebrospinal fluid. No matter what method of treatment was advocated, one must come back to the problem of how far one could treat the patient efficiently in the shortest time. Malaria had been a good therapeutic measure in a number of ways, but if one could bring about better results with penicillin, together with half the amount of malarial fever, and so complete the therapy, so much the better. Some patients were undoubtedly grossly overtreated and that was to be deprecated. If negative reactions could be obtained in two consecutive tests of the cerebrospinal fluid by the use of certain lines of treatment, and if the patient was well and at work, why worry him to continue treatment which was unnecessary?

Dr. Whelen said that there had been one question addressed to her about the length of time that the spirochaete lived after treatment. What she had put forward in her paper was a working hypothesis which, with increased knowledge, might quite well prove to be wrong. On the other hand, if it were assumed that the spirochaetes were killed soon after treatment, what was the explanation of the sero-relapses? Dr. Nicol had referred to the finding of penicillin in the cerebrospinal fluid. At Horton Hospital they were trying the effect of giving penicillin and malaria simultaneously. In the only case which they had so far been able to test, penicillin was found in the cerebrospinal fluid withdrawn one hour after an intramuscular injection of 300,000 units.

She wished to endorse what Dr. Osmond had said about the better outlook for the neurosyphilitic. If the patient came for treatment in time, one could be pretty sure of almost 100 per cent success.

\title{
Canadian legislation regarding venereal disease
}

According to a report in the July 1946 number of the Canadian Medical Association Journal, legislation is now in force in the Provinces of Alberta, Saskatchewan, British Columbia, Prince Edward Island and Manitoba requiring a premarital examination of both partners, including a blood test for syphilis, before the issuing of a marriage licence or the publication of banns. The details vary from one Province to another. In Prince Edward Island compulsory submission to treatment is enacted for persons suffering from venereal disease, and wide powers, including the right of search, are given to the Chief Health Officer. 